\title{
Robotic-assisted two-patch repair of right partial anomalous pulmonary venous connection and sinus venosus defect
}

Davorin Sef, MD, ${ }^{\mathrm{a}}$ Lawrence M. Wei, MD, ${ }^{\mathrm{b}}$ J. Scott Rankin, MD, ${ }^{\mathrm{b}}$ Charlotte R. Spear, MD,

Robert A. Gustafson, MD, ${ }^{\mathrm{b}}$ and Vinay Badhwar, MD, ${ }^{\mathrm{a}}$ London, United Kingdom, and Morgantown, WVa

From the ${ }^{a}$ Department of Cardiothoracic Surgery and Transplant Unit, Royal Brompton \& Harefield NHS Foundation Trust, Harefield Hospital, London, United Kingdom; and Departments of ${ }^{\mathrm{b}}$ Cardiovascular and Thoracic Surgery and ${ }^{\mathrm{c}}$ Surgery, West Virginia University, Morgantown, WVa.

Disclosures: The authors reported no conflicts of interest.

The Journal policy requires editors and reviewers to disclose conflicts of interest and to decline handling or reviewing manuscripts for which they may have a conflict of interest. The editors and reviewers of this article have no conflicts of interest.

Received for publication July 29, 2020; revisions received July 29, 2020; accepted for publication Aug 10, 2020; available ahead of print Aug 14, 2020.

Address for reprints: Vinay Badhwar, MD, Department of Cardiovascular and Thoracic Surgery, West Virginia University, 1 Medical Center Dr, Morgantown, WV 26506 (E-mail: vinay.badhwar@wvumedicine.org).

JTCVS Techniques 2020;4:262-4

2666-2507

Copyright (C) 2020 The Authors. Published by Elsevier Inc. on behalf of The American Association for Thoracic

Surgery. This is an open access article under the CC BY-NC-ND license (http://creativecommons.org/licenses/bync-nd/4.0/).

https://doi.org/10.1016/j.xjtc.2020.08.008

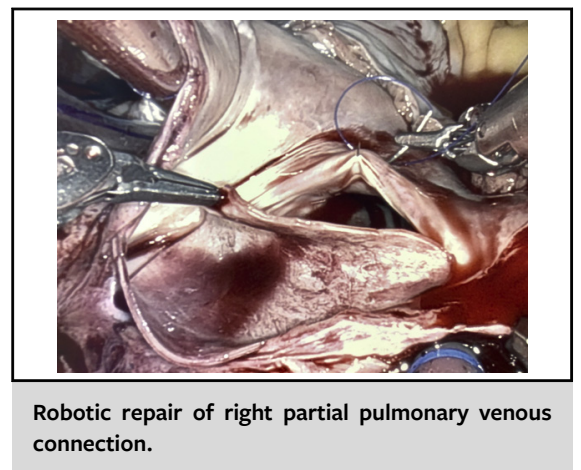

CENTRAL MESSAGE

PAPVCs remain uncommon, particularly in the adult. We present a repair of right partial pulmonary venous connection and sinus venosus defect with a 2-patch technique performed robotically.

See Commentaries on pages 265,267 , and 269

Partial anomalous pulmonary venous connection (PAPVC) consists of an abnormal drainage of 1 or more pulmonary veins into the systemic venous system. The incidence of PAPVC has been reported to be between $0.6 \%$ and $0.7 \%$, and it is commonly associated with a sinus venosus atrial septal defect (ASD). ${ }^{1,2}$ Initial presentation in adulthood remains uncommon.

Surgical repair can be successfully achieved via caval division and reconnection (Warden procedure), ${ }^{2,3}$ or a 2-patch technique to close the ASD while baffling the anomalous pulmonary venous return to the left atrium and expanding the cavoatrial confluence. ${ }^{1-3}$ The current case is a 2-patch repair performed robotically.

\section{CLINICAL SUMMARY}

A 114-kg, 30-year-old active male laborer with a body mass index of $33 \mathrm{~kg} / \mathrm{m}^{2}$ with no previous history of congenital or adult illness presented with increasing dyspnea on exertion with New York Heart Association class 3 symptoms. Transthoracic echocardiography identified a large ASD with significant enlargement of both the right atrium and right ventricle. This was further identified by transesophageal echocardiography (TEE) and computed

tomography angiography to be a right PAPVC draining both the right upper lobe and middle lobe into the posterior superior vena cava (SVC) $1.5 \mathrm{~cm}$ proximal to the cavoatrial junction via a sinus venosus defect. The patient was referred for correction, and he desired non-sternotomy possibilities. Fully informed consent was obtained for both sternotomy and minimally invasive options.

The patient was prepared with double-lumen endotracheal intubation, right internal jugular central line, and left upper-extremity arterial line. Cannulation was performed using Seldinger techniques and TEE guidance. The left internal jugular vein was cannulated with a 17French cannula and positioned in the mid innominate vein. The right common femoral vein was cannulated with a 25-French multistage venous cannula and the tip positioned in the mid right atrium. The right common femoral artery was cannulated with 19-French arterial cannula. A 4-cm right thoracotomy accessed the fourth intercostal space at the level of the anterior axillary line. The 


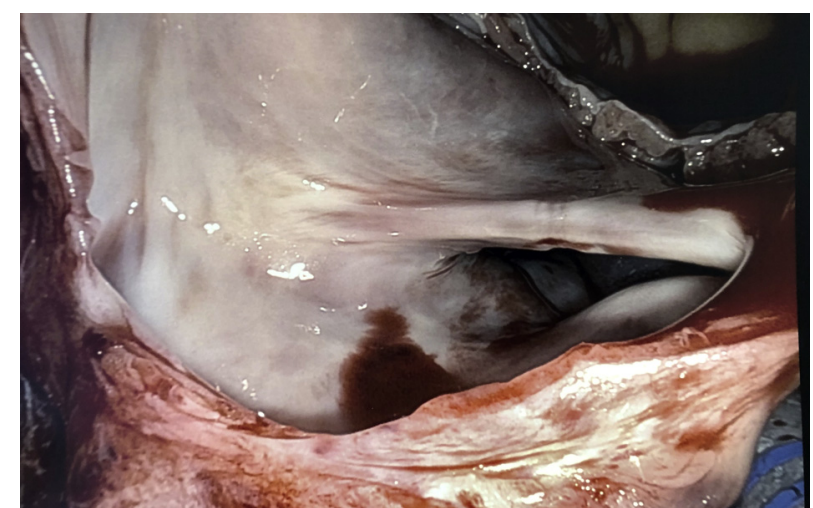

FIGURE 1. Intraoperative views showing right anomalous pulmonary venous connection of the right upper and middle veins draining into the right atrium and the sinus venosus atrial septal defect.

pericardium was incised $4 \mathrm{~cm}$ anterior to the phrenic nerve and retracted laterally. Cardiopulmonary bypass (CPB) with vacuum-assisted drainage was instituted, and an aortic root vent was placed. A left ventricular vent was placed under TEE guidance via right inferior pulmonary vein. The DaVinci Xi robotic surgical system (Intuitive Surgical, Sunnyvale, Calif) was docked and its arms were introduced through 3 ports in the third, fifth, and seventh intercostal space. The distal ascending aorta was crossclamped and myocardial arrest was achieved and maintained with antegrade blood cardioplegia.

Under full robotic assistance, the lateral SVC was curvilinearly incised from the level of the azygous vein to the mid right atrium. The sinus venosus ASD and its confluence with the right upper lobe and right middle lobe PAPVC resulted in a defect of the posterior wall of the SVC and atrial septum measuring $3.5 \times 4.5 \mathrm{~cm}$ (Figure 1). This area was baffled with a bovine pericardial patch using running 40 polypropylene suture (Figure 2). After de-airing, a second elliptical patch was used for a closure of the SVC to enlarge the cavoatrial junction (Figure 3 and Video 1). Atrial and ventricular pacing wires were robotically placed and the crossclamp removed. The patient was weaned off $\mathrm{CPB}$ in sinus rhythm. Crossclamp time was 141 minutes and total CPB time was 190 minutes.

The patient was extubated in the operating room and transferred to the intensive care unit. He was discharged on the fifth postoperative day in sinus rhythm. At 30-day clinical follow-up, he was in New York Heart Association class 1 , normal sinus rhythm, with a normal right ventricle size and no residual defect by transthoracic
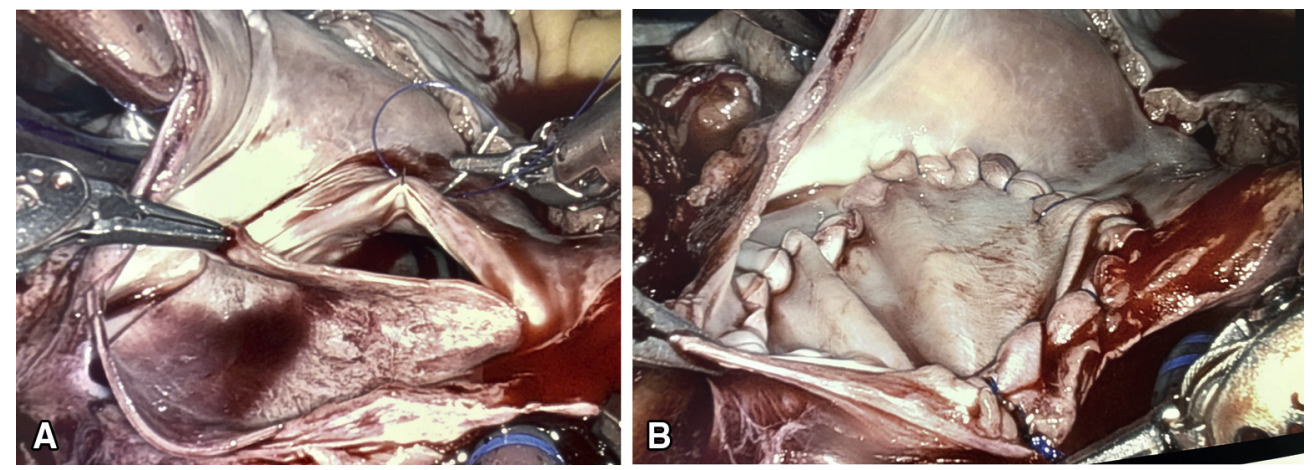

FIGURE 2. The anomalous right upper and middle pulmonary veins were baffled with a bovine pericardial patch (A) to allow unobstructed flow from the anomalous veins into the left atrium after completion (B).
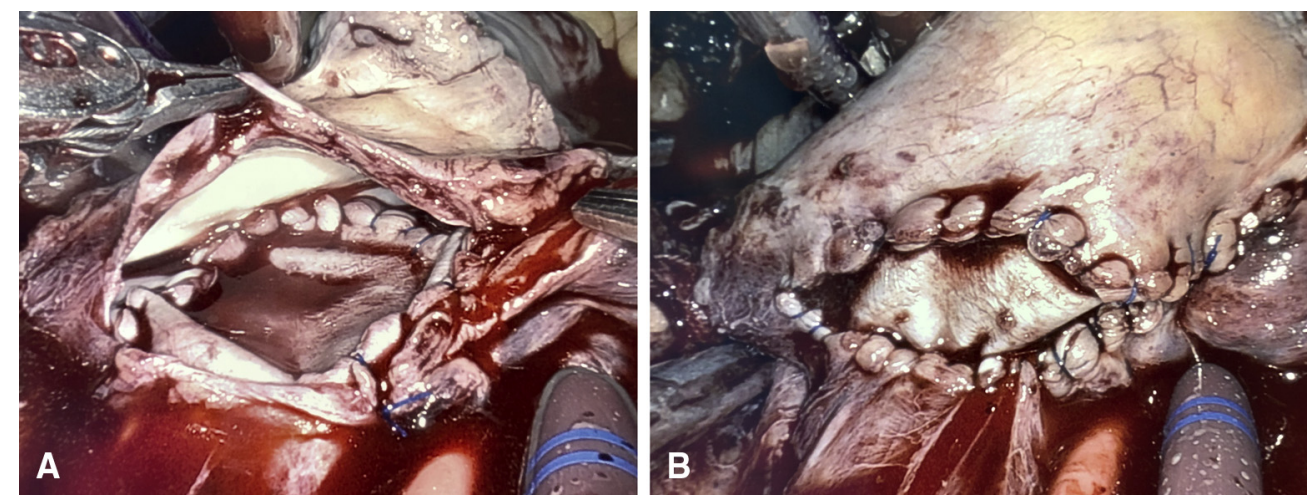

FIGURE 3. Defect of superior vena cava and cavoatrial junction, before (A) and after (B) patch augmentation that was performed to mitigate potential cavoatrial restriction. 


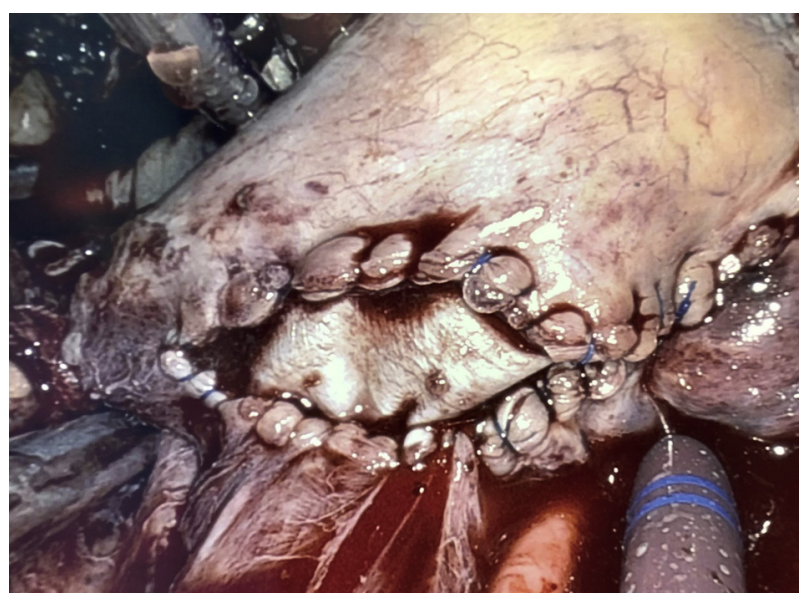

VIDEO 1. Case presentation and technique of robotic-assisted 2-patch repair of right anomalous pulmonary venous connection used to treat a symptomatic 30-year-old, 114-kg adult man. Video available at: https:// www.jtcvs.org/article/S2666-2507(20)30383-7/fulltext.

echocardiography, and a widely patent SVC. At 6 months, the patient is symptom free and he is working as a hard laborer without difficulty or dyspnea. Patient consent was obtained to contribute this experience.

\section{DISCUSSION}

Surgical repair of PAPVC and ASD using a 2-patch technique requires creating a baffle to direct anomalous pulmonary venous drainage to directly enter the left atrium and a second patch so as not obstruct the SVC or pulmonary veins. ${ }^{1}$ Robotically assisted right chest approach to intracardiac surgery has been showed to be safe, effective, and may be equivalent to sternotomy in experienced centers. ${ }^{4}$ Other attempts have been made at single-patch robotic approaches to ASD repair with or without the presence of a left sided SVC. ${ }^{5,6}$
Onan and colleagues ${ }^{7}$ performed a successful robotic single patch closure of a $1.4 \times 2.0$-cm secundum ASD and PAPVC defect in a 20 year old female patient. Our patient was a robust $114-\mathrm{kg}$ male patient with a proximal sinus venous defect and high insertion of both the upper and middle lobe veins, in whom we felt that preserving unobstructed SVC flow was essential. Therefore, a 2-patch technique was selected and performed robotically facilitated by vacuum-assisted drainage without snaring. The patient successfully returned to work 6 weeks following his operation.

\section{CONCLUSIONS}

Robotically assisted right PAPVC and ASD repair with a 2-patch technique can be performed safely in the adult.

\section{References}

1. Said SM, Burkhart HM, Schaff HV, Cetta F Jr, Phillips SD, Barnes RD, et al. Single-patch, 2-patch, and caval division techniques for repair of partial anomalous pulmonary venous connections: does it matter? J Thorac Cardiovasc Surg. 2012;143:896-903.

2. Gustafson RA, Warden HE, Murray GF, Hill RC, Rozar GE. Partial anomalous pulmonary venous connection to the right side of the heart. J Thorac Cardiovasc Surg. 1989;98:861-8.

3. Shahriari A, Rodefeld MD, Turrentine MW, Brown JW. Caval division technique for sinus venosus atrial septal defect with partial anomalous pulmonary venous connection. Ann Thorac Surg. 2006;81:224-9.

4. Coyan G, Wei LM, Althouse A, Roberts HG, Schauble D, Murashita T, et al. Robotic mitral valve operations by experienced surgeons are cost-neutral and durable at 1 year. J Thorac Cardiovasc Surg. 2018;156:1040-7.

5. Lews CTP, Bethencourt DM, Stephens RK, Cline JL, Tyndal CM. Robotic repair of sinus venosus atrial septal defect with partial anomalous pulmonary venous return and persistent left superior vena cava. Innovations. 2014;9:388-90.

6. Bacha EA, Bolotin G, Consilio K, Raman J, Ruschhaupt DG. Robotically assisted repair of sinus venosus defect. J Thorac Cardiovasc Surg. 2005;129: 442-3.

7. Onan B, Aydin U, Turkvatan A, Bakir I. Robot-assisted repair of right partial anomalous pulmonary venous return. J Card Surg. 2016;31:394-7. 